\title{
Editorial - The integration of infrastructures as a response to climate change: a critical opportunity?
}

\author{
Richard Dunning ${ }^{1}$ and Nick Taylor Buck ${ }^{2 *}$ \\ 1 University of Liverpool \\ 2 University of Sheffield
}

The resilience of cities to climate change is one of the greatest contemporary academic and policy topics. Its political significance has risen rapidly in the early $21^{\text {st }}$ century, shaping urban policy agendas and territorial governance at multiple spatial scales (Bulkeley and Betsill, 2013). Much ink has been used in debating the definition of 'resilience' throughout a diverse academic literature (Leichenko, 2011; Beilin and Wilkinson, 2015; Meerow et al., 2016). Yet, despite its ambiguity resilience has also acted as a bridging concept in urban infrastructure analysis, drawing together disparate fields from across social sciences and engineering (Davoudi, 2012). In this context resilient infrastructure has emerged as one of the key loci for discussion at the nexus of material systems and political discourse in response to climate change (Cimellaro et al., 2016).

Arguments around the influence of the 'perfect storm' of urbanization and climate change-related extreme weather events on urban system resilience have been frequently rehearsed in the planning and policy literature (e.g. While and Whitehead, 2013). The basic tenets are that as the proportion of the global population living in urban environment continues to rise above 50 per cent (United Nations, 2011), urban demand for infrastructure services will rise, anthropogenic climate change will increasingly be affected by urban performance, which in turn will affect the ability of infrastructure to meet the demands made upon it. There is therefore a need to consider the construction or adaptation of new forms of infrastructure to ensure the resilience of urban Social-Ecological-Technical Systems (SETS) (Grimm et al., 2016), such as New York's Green Infrastructure Program (The City of New York Department of Environmental Protection, 2016), the Staten Island Bluebelt (NYC Environmental Protection, 2016) and the Dutch government's Delta programme (Netherlands Government, 2016)

Critics of the way in which this discourse has been operationalized politically have questioned its passivity in simply accepting climate change as a brute fact that necessitates infrastructural adaptation (Evans, 2011). Whilst this critique carries weight, it does not preclude the same frame producing a more hopeful response, chiefly that infrastructure adaptation might act to not only support the ongoing provision of services, but also limit the oppositional stance of human and non-human co-existence. 


\section{p. 2. Editorial - The integration of infrastructures as a response to climate change: a critical opportunity?}

The development and management of the diverse infrastructure requirements of key urban areas has been characterised as fractured. Many national and city-region scale governance practices are splintered across infrastructure types, so that no individual organization has a clear view of the relationship between infrastructures (Graham and Marvin, 2001). Single service infrastructure policy silos and independent business structures are therefore incapable of acting in a coordinated manner. Yet the challenges of climate change and urbanisation are interconnected in cities. Examples of the interdependencies between infrastructural systems are not difficult to imagine, for example a storm drain failing during a flood may create chaos in the localised transportation and waste water networks, which could have wider food and energy impacts for nearby hospitals, schools, and care homes. We also need energy to produce artificial fertilizers to feed our crops and to power agricultural equipment to support this productivity, and vehicles to distribute the food. As a result, there is a clear link between the price of oil and the price of food. Systemic and cascading shocks are often overlooked in much academic research yet they are an inevitable consequence of the complex and tightly-coupled systems that make up the modern world. The unique context and character of each urban area will influence the precise composition of these connected infrastructure challenges and its vulnerability to extreme weather events and climate change (Gasper et al., 2011).

The opportunities to integrate multiple services into single infrastructure systems are rapidly becoming achievable through advances in technology and, crucially, the application of existing knowledge to infrastructure problems. The 'city blood' idea for example, in which combined water and energy is transported through existing water supply networks, obviating the need for separate energy and water networks, is a vision for the future that is being considered as an increasingly feasible design option in the present (Karaca et al., 2013). Other examples of integrated infrastructures could include: photovoltaic roadway acoustic barriers (Oltean-Dumbrava \& Miah, 2016); 'living machines' such as the Urban Municipal Canal Restorer in Fuzhou, China, where water treatment, green infrastructure and pedestrian transport were combined (Todd, 2002); anaerobic digestion of waste solids to produce biogas (Bieker et al., 2010); and photocatalytic and photoelectrochemical (PEC) water splitting to produce Hydrogen (Abe, 2010).

One response has been to suggest that the design of resilient infrastructures, within the context of limited resources, could benefit from both the integration of multiple types of infrastructure and the integration of the social structures that determine the priorities, resources and potential solutions of the resilience adaptation process (e.g. Ness, 2008).

Integrated infrastructure, in this context, is therefore defined as the combination of more than one physical infrastructure 'type' (e.g. energy, water, transport, food, waste, ICT, and green infrastructures) and interdisciplinary analysis. Integrated infrastructure objects of inquiry could include: the role of integrated planning (e.g. between water and energy in the construction of the infrastructure) in city resilience; the capacity of integrated delivery organisations (e.g. a multi-utility service company or MUSCo) in delivering sustainable services; and the integration of emergency planning systems to mitigate the impact of extreme weather events. Approaching infrastructure in this manner could allow for synergistic social science and engineering dialogue in the design, delivery and management of infrastructure. It would envision infrastructure adaptations as both an agent for resilience and as a (positive) contribution to the human-centric impact on the non-human world, whilst recognizing and reflecting the centrality of infrastructures to the political, social and economic ecosystems which they contribute to and function for. 


\section{p. 3. Editorial - The integration of infrastructures as a response to climate change: a critical opportunity?}

The dual integration of both urban infrastructure 'types' and socio-structural integration have been practically relevant and theoretically developed separately in isolated social scientific disciplines, and require combining (Monstadt, 2009). Whilst there has been widespread interest amongst engineers (both practitioners and academics) and amongst policy makers regarding the potential to integrate multiple infrastructure types, the literature has tended to focus on either the integration of more than one infrastructure type or on socio-technical integration of a single type (e.g. the Journal of Structural Engineering special issue on resilience (142(8)). In a review of the literature on interconnected infrastructure and climate change from a socio-technical stance, Chappin and van der Lei (2014) found that there were very few studies that brought these topics together, but they did suggest that this might change in the coming years. This special issue is a response to the international clamour for the integration of infrastructures, and supports the endeavour to populate the literature with a dual multi-type and socio-technical integrated infrastructure approach.

\section{Overview of papers}

In February 2016 we were contacted by Dr Thomas Wilbanks' about this special issue, in which he outlined his desire to write a summary of existing knowledge and the context of contemporary infrastructure integration research in the USA. Sadly before he could see this special issue come to fruition, in January of this year, Dr Wilbanks passed away. Dr Wilbanks' knowledge and work on climate change, sustainable development and environmental technology was extensive and his research contribution was well recognized formally, not least through the Intergovernmental Panel on Climate Change's co-award for the 2007 Nobel Prize for Peace. Further information about Thomas Wilbanks' work is available from the American Association of Geographers, who have established the AAG Wilbanks Award for Transformational Research in Geography in his memory. We are grateful to Dr Wilbanks' family and colleagues for their encouragement to publish his contribution.

Wilbanks' paper charts the silos of infrastructure decision making in the United States, recognising that integration has not always occurred intentionally nor strategically. It discusses the fragmentation of infrastructure management responsibilities resulting from sectoral and public / private sector divisions, and drivers for integration come from diverse sources. The article focuses on infrastructure integration between energy and water resource systems with the suggestion that such integration will increase in the US in coming years through bottom-up incentive-driven initiatives. Wilbanks' argues that focus and a shared vision are needed for effective integration, and that initially this could centre on shared, visible commitment to green infrastructure or a shared responsibility for emergency preparedness. In short, infrastructure integration can be expected to evolve through partnerships rather than edicts.

Expanding beyond the USA, McLean outlines the institutional differences affecting infrastructural governance in the USA, the UK and Germany. Incentivising, enabling, and coordinating classifications of state infrastructural management structures are considered to highlight the differences in the ability of infrastructural governance systems to respond to context-specific needs and desires via vertical (i.e. federal, state, local) and horizontal (i.e. business, unions and third parties) integration. The analysis points to a predisposition toward vertical infrastructural integration in the US and UK as opposed to the horizontal multi-sectoral provision seen in Germany. This would mean that significant change in US/UK central government policy would be necessary to exploit any benefits of infrastructure integration. McLean concludes that institutional 
differences between specific infrastructures, and between specific cities and urban regions within countries that exemplify differing models of state have clear impacts on the development of infrastructural networks, and that they must be factored into research involving any international or inter-urban comparisons of the success (or failure) of infrastructural integration.

In the third paper, Ness and Asad adopt a systems approach in considering how climate change is impacting the city of Khulna in Bangladesh and how the UN framework for integrating infrastructure has supported a localised approach to conceptualising and responding to the city's water challenges. They argue that centralised 'hard' engineering solutions to infrastructural challenges often overlook key components at the local scale. Through understanding indigenous culture and knowledge in their case study, framed in an integrated system of formal infrastructure and climate change understanding, they find that achieving improvements in both flood resilience and community objectives are possible.

Within the context of widespread policy engagement with integrated infrastructures the last of our papers takes a critical approach to the very definition of infrastructure, and the various modes of its integration. In it Raven tackles two key questions; firstly, does infrastructure ever occur without integration, and if not, what does 'integration' actually mean? Second, should infrastructure be considered a response or causal factor in anthropogenic climate change? In doing so, he offers a functional definition of 'concrete' infrastructure, and investigates possible social and technical interpretations of the phrase "integrated infrastructure". He concludes that the technical integration of infrastructure is effectively a fait accompli that does not of itself provide appropriate climate change responses, whilst the social integration of infrastructure underpins a sociotechnical utopian vision which may guide us towards more just infrastructural configurations in the future. As such social integration of infrastructure is the more desirable and achievable goal that addresses the complex relationships between space, place and resource distribution.

Together these papers provide a strong critique of the notion of integrated infrastructure, and a significant contribution to ongoing debate. Whilst the concepts behind infrastructural integration are not new, their absence in practice has hindered cities' adaptive capacities to the challenges of climate change. These papers show that integrated infrastructure remains both a contested concept and a complex end. Nevertheless, all of the authors remain hopeful that policy and practice may adapt to produce climate change resilient integrated infrastructures that support and enhance urban ecosystems.

Further empirical investigation is needed to understand the circumstances in which the integration of infrastructures has had a positive (and negative) impact, and to understand the key agencies involved in its successful implementation. It is imperative that this work takes a critical stance, highlighting both barriers to implementation and circumstances in which integration actually runs counter to resilience and wider sustainability. However, we remain hopeful that in many urban contexts infrastructure integration has the potential promote debate and paradigm shifts that could result in more resilient services, innovative governance, finance and management models, and reduction in the negative environmental impacts associated with infrastructure development and management.

We are grateful to the authors of these articles for stimulating the ensuing debate, to their dedication in seeking to understand our world and to convey their research to others. We are grateful to the family and colleagues of Dr Wilbanks' for supporting the publication of his article, as well as to all of the reviewers and editors of People, Place and Policy for recognising the importance of infrastructure development for both our 
cities and the climate. We are thankful too to the World Universities Network for funding the initial collaborative discussions behind this special issue and look forward to the future development of this critique.

* Correspondence address: Richard Dunning, Department of Geography and Planning, University of Liverpool. Email: r.j.dunning@liverpool.ac.uk / Nick Taylor Buck, Urban Institute, University of Sheffield. Email: n.taylor-buck@sheffield.ac.uk

\section{References}

Abe, R. (2010) Recent Progress on Photocatalytic and Photoelectrochemical Water Splitting under Visible Light Irradiation. Journal of Photochemistry and Photobiology C: Photochemistry Reviews, 11, 4, 179-209.

Bieker, S., Cornel, P. and Wagner, M. (2010) Semicentralised Supply and Treatment Systems: Integrated Infrastructure Solutions for Fast Growing Urban Areas. Water Science \& Technology, 61, 11, 2905-13.

Beilin, R. and Wilkinson, C. (2015) Introduction; Governing for urban resilience. Urban Studies, 52, 7, 1205-1217.

Bulkeley, H. and Betsill, M.M. (2013) Revisiting the urban politics of climate change. Environmental Politics, 22, 1, 136-154.

Chappin, E.J.L. and van der Lei, T. (2014) Adaptation of interconnected infrastructures t climate change: A socio-technical systems perspective. Utilites Policy, 31, 10-17.

Cimellaro, G., Dueñas-Osorio, L. and Reinhorn, A. (2016) Special Issue on ResilienceBased Analysis and Design of Structures and Infrastructure Systems. Journal of Structural Engineering, 142, 8.

Davoudi, S. (2012) Resilience: A Bridging Concept or a Dead End? Planning, Theory \& Practice, 13, 2, 299-307.

Evans, J.P. (2011) Resilience, ecology and adaptation in the experimental city. Transactions of the Institute of British Geographers, 36, 2, 223-237.

Gasper, R., Blohm, A. and Ruth, M. (2011) Social and economic impacts of climate changes on the urban environment. Current Opinion in Environmental Sustainability, 3, 3, 150-157.

Grimm, N. B., Cook, E. M., Hale, R. L. and Iwaniec, D. M. (2016) A Broader Framing of Ecosystem Services in Cities: Benefits and Challenges of Built, Natural, or Hybrid System Function. The Routledge Handbook of Urbanization and Global Environmental Change. Routledge.

Karaca, F., Camci, F. and Raven, P.G. (2013) City blood: A visionary infrastructure solution for household energy provision through water distribution networks. Energy, 61, 1, 98-107.

Leichenko, R. (2011) Climate change and urban resilience. Current Opinion in Environmental Sustainability, 3, 3, 164-168.

Meerow, S., Newell, J.P. and Stults, M. (2016) Defining urban resilience: A review. Landscape and Urban Planning, 147, 38-49.

Monstadt, J. (2009) Conceptualizing the political ecology of urban infrastructures: insights from technology and urban studies. Environment and Planning A, 41, 8, 1924-1942.

Ness, D. (2008) Sustainable urban infrastructure in China: Towards a Factor 10 improvement in resource productivity through integrated infrastructure systems. International Journal of Sustainable Development \& World Ecology, 15, 4, 288301.

Netherlands Government. (2016) Delta Programme. government.nl. Available at: https://www.government.nl/topics/delta-programme 
p. 6. Editorial - The integration of infrastructures as a response to climate change: a critical opportunity?

NYC Environmental Protection. (2016). The Staten Island Bluebelt. nyc.gov. Available at: http://www.nyc.gov/html/dep/html/stormwater/bluebelt.shtml

Oltean-Dumbrava, C. and Miah, A. (2016) Assessment and Relative Sustainability of Common Types of Roadside Noise Barriers. Journal of Cleaner Production, 135.

The City of New York Department of Environmental Protection (2016) Green Infrastructure Performance Metrics Report. New York.

Todd, J. (2002) Urban Municipal Canal Restorer Fuzhou, China Case Study. Available at: $\quad$ http://toddecological.com/clients/PDFs/100623.casestudy.baima.pdf [Accessed: 13/01/2014]

While, A. and Whitehead, M. (2013) Cities, Urbanisation and Climate Change. Urban Studies, 50, 7, 1325-1331. 